\title{
Army Helicopter Casualty Evacuations in Belize in 1995 and 1996
}

\author{
Maj AJ Eke \\ MB, BS, DIH, MFOM, DAvMed, RAMC* \\ Senior Specialist in Aviation Medicine
}

Aviation Branch, Headquarters Land Command, Airfield Camp, Netheravon, Salisbury, Wilts, SP4 9SF.

SUMMARY: Since the withdrawal of Royal Air Force Puma helicopters from Belize in 1994, the role of casualty $\frac{\overline{\bar{\rho}}}{\vec{P}}$
evacuation (CASEVAC) of British military personnel, Belizean citizens and foreign nationals throughout the country,
has passed to 25 Flight Army Air Corps, currently equipped with Gazelle helicopters. Details of casualty evacuations
during 1995 and 1996 have been collated and analysed in order to provide information on casualty types, and the
locations from which casualties have been evacuated, during this 2 year period. The data so obtained might be used
to ensure the future provision of an appropriately equipped CASEVAC helicopter, or to highlight common causes of $\overline{\vec{\omega}}$
significant morbidity in British troops deployed to Belize.

\section{Background}

Belize is a developing country to the east of Guatemala and south of Mexico in Central America, approximately the size of Wales, and with a total population of some 216,000 (Fig 1). The country's topography can be divided into 4 main regions: a northern flat plain, with some cultivated areas and other areas covered in dense scrub and trees; a central mountain range, with steep sided hills covered in dense secondary jungle; a more undulating southern region, also covered in secondary jungle; and a low coastal plain covered in mangrove swamp. There are, in addition, hundreds of small islands, or cayes, strung along the longest barrier reef in the western hemisphere.

The climate of Belize is tropical, hot and humid. Daytime temperatures range from 25 to $35^{\circ} \mathrm{C}$ during the year, remaining high throughout the night in the lower-lying areas but falling to $4^{\circ} \mathrm{C}$ in the mountains. Relative humidity is consistently in the high $90 \% \mathrm{~s}$. The rainy season is between June and January, although tropical storms produce heavy rainfall throughout the year, and the hurricane season occurs between July and November.

The Belizean economy is based mainly on agriculture, especially on sugar cane and citrus fruits, although tourism is becoming increasingly important with growing recognition of the natural assets of the unspoilt interior of the country, and the beauty of the cayes and reef. At present the majority of tourists originate from the United States.

The Belizean population is divided so that approximately half live in the 7 major cities, with the remainder in a number of smaller towns, and small isolated settlements in remote areas. Hospitals are located in Belize City, Belmopan, Punta Gorda, Orange Walk, and Dangriga, although only the former has facilities to deal with significant trauma or surgical, medical or obstetric emergencies. Transport communication between the centres of population is improving, but remains very poor by western standards. The majority of the lengths of the 4 national highways is unmetalled, with frequent potholing, and impassable flooding after tropical storms. Road travel times between the more distant major centres and Belize
City may exceed 12 hours, and night-time travel işم particularly hazardous.

Helicopters have a number of uses in casualty care:ct improvement of response time where casualties are in remote areas; earlier delivery of advanced medicalo intervention; increased speed in transportation of the casualty; direct delivery to the most appropriate specialigst centre; and interhospital transfers (1). It is now we recognised that the prognosis for injured casualties 95 worsened by delay in receiving advanced medical care. severely injured patients, the mortality rate has beinge observed to increase by $300 \%$ for every 30 minutes' delgy. in treatment, and the use of helicopters for rapid evacuatigno of casualties in conflict has been given as the most likey cause of the progressive reduction in casualty mortali rates (2).

Transportation of casualties by helicopter is, however邑 associated with a number of disadvantages. The environment inside the aircraft is extremely noisy? rendering communication difficult and preventing use of techniques such as auscultation in flight. There is considerable vibration, which makes delicate manual tasks. even more difficult, and can exacerbate both pain and haemorrhage. Dependent on the type of helicopter in use, there may be limitations on space available, with patient care being hindered in small aircraft with cramped cabin spaces. There will also be a limit to the amount of equipment and/or attendants which may be carried, aso many helicopters operate close to maximum weight limits In addition, there are constraints on the operation of helicopters in poor weather conditions. Helicopters do no⿸ have an all-weather capability.

Until late 1994, a helicopter Search and Rescue ands casualty evacuation service was provided to British ande. Belizean Military personnel, Belizean civilians (including the Belize Defence Force or BDF) and foreign nationals (predominantly tourists but also including British nationalso on Operation Raleigh, and staff of the British Hight Commission) by the Pumas of 1653 Squadron, Royal Aip Force. 1653 Squadron was based at Airport Camp, some 20o 
minutes by road from Belize City. The Puma is a medium Support Helicopter with a crew of 3 , and a seated passenger capacity of 14. In addition, the Puma can be fitted with a winch which is clearly invaluable in operations over dense jungle terrain. The Puma support was withdrawn with departure of the RAF contingent from Belize in 1994. At this time the role of providing a 24 hour casualty evacuation service $^{1}$ for the entire country was passed to 25 Flight, Army Air Corps who are currently equipped with Gazelle helicopters. The Gazelle is a small light reconnaissance helicopter, with a crew of one or 2 pilots, and further seating for 2 to 3 passengers. If a lying casualty is to be carried, the left-hand front seat and flying controls are removed, and a Bofors Splint stretcher must be used in order to fit the casualty's feet into the small rear baggage space. This leaves room only for a single seated attendant in the rear, who has restricted access to the patient in flight. For night CASEVACs of a lying casualty, single-pilot Night Vision Goggle (NVG) flight must be carried out. This is a risky procedure which is not generally authorised for Army Aviation operations. There is no facility for winching from the Gazelle, so for jungle evacuations either the patient must be transported through the jungle to a cleared area, or a new landing site area cut laboriously from the jungle at the pick-up point.

Despite the apparent constraints on carriage of casualties in the Gazelle, 25 Flt AAC have been regularly, and successfully, tasked with CASEVAC since the departure of 1653 Squadron in 1994. This paper analyses the details of helicopter CASEVACs carried out by 25 Flt AAC during 1995 and 1996.

\section{Results}

During 1995 and 1996 a total of 192 casualties were evacuated by the Gazelles of 25 Flt AAC. These have been broken down into population groups (British military/dependants, Belizean nationals, and foreign nationals including British civilians), into diagnostic groups, and according to location from which the evacuation took place (jungle, mountains, cayes or towns).

Records for 1995 show that 77 British military, 23 Belizeans, and 13 foreign national casualties were evacuated, totalling 113 persons. For 24 of these, part or all of the evacuations took place at night. In 1996, the total of 79 casualties was comprised of 42 British military personnel, 26 Belizeans and 11 foreign nationals. Twelve of these CASEVACs took place at night. Over the 2 years, 6 casualties were BDF or MoD Employees (included in the Belizean national totals), and 5 were British expedition members on Operation Raleigh (included in the Foreign national totals).

' A limited casualty evacuation service is provided for civilians, in daylight hours only, by a small fixed-wing aircraft operated by a local tourist air-charter company. This can only operate where casualties are close to an airstrip which are generally located only near the major population centres.
Table 1.

British Military CASEVACs $1995 / 6$ by cause.

\begin{tabular}{|c|c|c|c|c|c|c|c|c|c|}
\hline & Aecidents & Assaull & Heal & $\begin{array}{c}\text { Bilts' } \\
\text { Stings }\end{array}$ & Diving & Med & Surg & Obstetric & $\begin{array}{c}\text { Ford } \\
\text { Poisoning }\end{array}$ \\
\hline $\mathbf{1 9 9 5}$ & 43 & 0 & 14 & 4 & 0 & 8 & 0 & 0 & 8 \\
\hline $\mathbf{1 9 9 6}$ & 19 & $\overline{0}$ & 11 & 3 & 0 & 4 & 4 & 0 & 1 \\
\hline Total & 62 & 0 & 25 & 7 & 0 & 12 & 4 & 0 & 9 \\
\hline
\end{tabular}

Table 2.

Belizian National CASEVACs 1995/6 by cause.

\begin{tabular}{|c|c|c|c|c|c|c|c|c|c|}
\hline & Accidents & Assault & Heat & $\begin{array}{c}\text { Bites } \\
\text { Stings }\end{array}$ & Diving & Med & Surg & Obstetric & $\begin{array}{c}\text { Food } \\
\text { Poisoning }\end{array}$ \\
\hline $\mathbf{1 9 9 5}$ & 7 & 1 & 2 & 0 & 1 & 1 & 4 & 4 & 3 \\
\hline $\mathbf{1 9 9 6}$ & 9 & 4 & 0 & 1 & $\overline{0}$ & $\overline{5}$ & 2 & 5 & 0 \\
\hline Total & 16 & 5 & 2 & 1 & 1 & 6 & 6 & 9 & 3 \\
\hline
\end{tabular}

Table 3.

Foreign National CASEVACs $1995 / 6$ by cause.

\begin{tabular}{|c|c|c|c|c|c|c|c|c|c|}
\hline & Accidents & Assault & Heat & $\begin{array}{c}\text { Bites } \\
\text { Stings }\end{array}$ & Diving & Med & Surg & Obstetric & $\begin{array}{c}\text { Food } \\
\text { Poisening }\end{array}$ \\
\hline 1995 & 3 & 2 & 0 & 1 & 2 & 2 & 2 & 0 & 1 \\
\hline 1996 & 5 & 0 & 0 & 2 & 0 & 3 & 1 & 0 & 0 \\
\hline Total & 8 & 2 & 0 & 3 & 2 & 5 & 3 & 0 & 1 \\
\hline
\end{tabular}

The predominant causes for evacuation of British military personnel were injury resulting from accidents $(620$ in total over the 2 year period, representing $52 \%$ ), and heaा illness (25 casualties over 2 years, or $21 \%$ )(Table 1). The most common categories for Belizean casualties were accidents $(16$, or $32 \%)$, and obstetric emergencies $(9$, of $18 \%$ ) (Table 2). Foreign nationals were also most likely to̊ require CASEVAC following accidents $(8$, or $33 \%)$, with medical problems $(5$, or $21 \%)$ as the second commones cause (Table 3). Scrutiny of the causative factors in more detail reveals that over the 2 year period, 18 of the British military casualties were evacuated for eye injuries caused by tree sap, released whilst cutting jungle foliage. A number of these were injured after cutting a jungle landing site for evacuation of a colleague.

Most British military casualties were evacuated from jungle locations $(89$, or $75 \%)$, or mountain sites $(18$, or $15 \%$ )(Table 4). Belizean nationals were most likely to require evacuation from towns (21, or $43 \%$ ) or jungle locations (18, or $37 \%$ ) (Table 5). In contrast, foreign nationals were CASEVACed predominantly from the cayes $(11$, or $46 \%)$ (Table 6).

Table 4.

British Military CASEVACs $1995 / 6$ by location.

\begin{tabular}{|c|c|c|c|c|}
\hline & Jungle & Mountain & Cayes & Town \\
\hline $\mathbf{1 9 9 5}$ & 54 & 17 & 4 & 2 \\
\hline $\mathbf{1 9 9 6}$ & 35 & 1 & 1 & 5 \\
\hline Total & 89 & 18 & 5 & 7 \\
\hline
\end{tabular}

Table 5.

Belizean National CASEVACs 1995/6 by location.

\begin{tabular}{|c|c|c|c|c|}
\hline & Jungle & Mountain & Cayes & Town \\
\hline 1995 & 7 & 0 & 7 & 9 \\
\hline 1996 & 11 & 0 & 3 & 12 \\
\hline Total & 18 & 0 & 10 & 21 \\
\hline
\end{tabular}




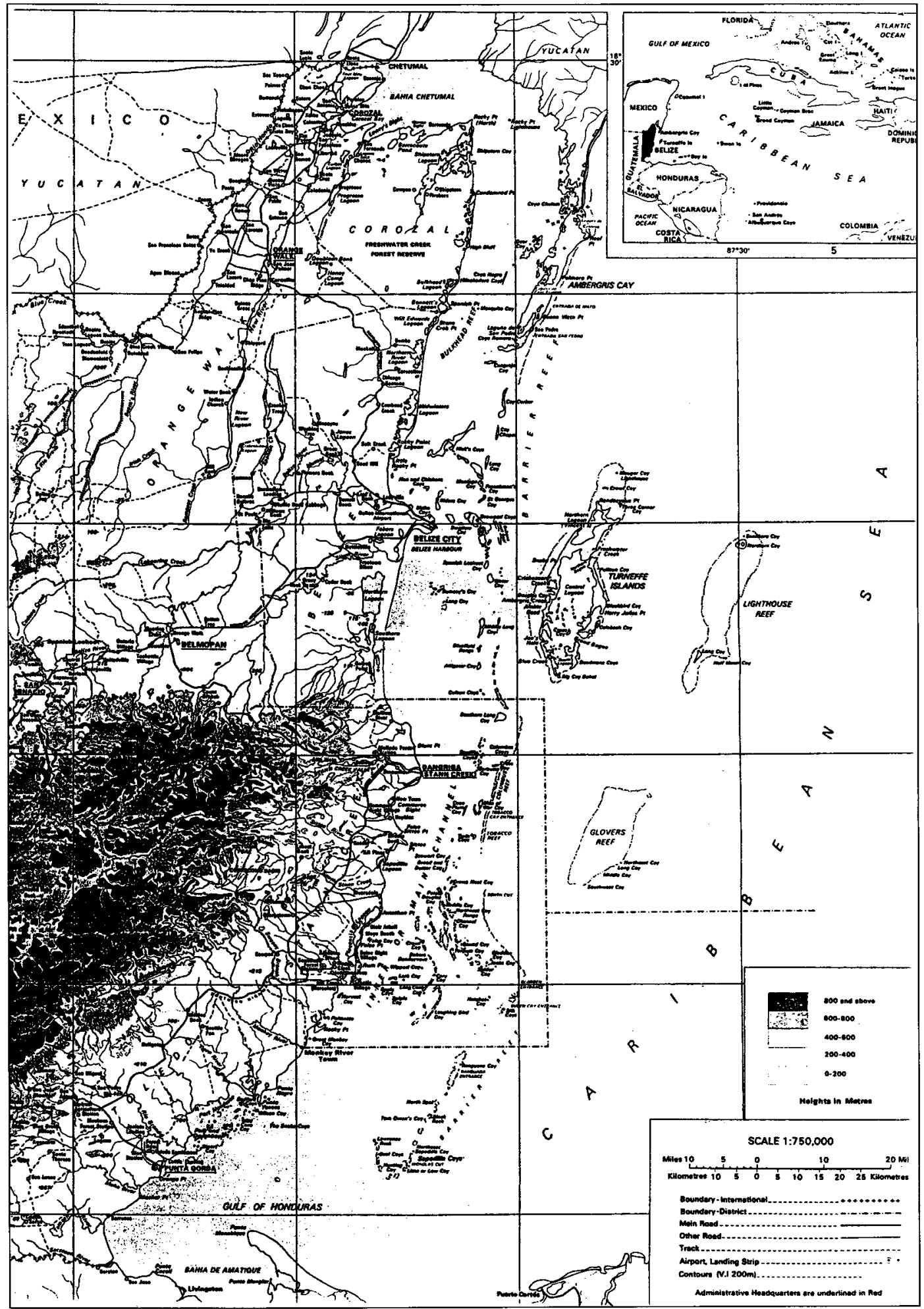

Fig 1. Map of Belize. 
Table 6.

Foreign National CASEVACs $1995 / 6$ by location.

\begin{tabular}{|c|c|c|c|c|}
\hline & Jungle & Mountain & Cayes & Town \\
\hline $\mathbf{1 9 9 5}$ & 3 & 0 & 6 & 4 \\
\hline 1996 & 4 & 0 & 5 & 2 \\
\hline Total & 7 & 0 & 11 & 6 \\
\hline
\end{tabular}

Table 7.

CASEVACs 1995/6: Totals by Location and Cause.

\begin{tabular}{|c|c|c|c|c|c|c|c|c|c|}
\hline & Aceidents & Assault & Heat & $\begin{array}{c}\text { Bites } \\
\text { Stings }\end{array}$ & Diving & Med & Surg & Obstetric & $\begin{array}{c}\text { Fond } \\
\text { Poisoning }\end{array}$ \\
\hline Jungle & 49 & 0 & 26 & 8 & 0 & 12 & 8 & 0 & 11 \\
\hline Mountain & 11 & 0 & 1 & 2 & 0 & 3 & 0 & 0 & 1 \\
\hline Cayes & 12 & 3 & 0 & 1 & 3 & 3 & 1 & 3 & 0 \\
\hline Town & 14 & 4 & 0 & 0 & 0 & 5 & 4 & 6 & 1 \\
\hline
\end{tabular}

Victims of assault and obstetric patients were evacuated from only town or caye locations, whereas accident victims were distributed amongst all 4 location groups: jungle, mountains, cayes and towns. Heat casualties, food poisoning cases and victims of bites or stings were almost exclusively rescued from jungle locations, and medical and surgical problems were more likely to result in CASEVAC from jungle sites, but also occurred at the other location types. Not surprisingly, all 3 diving casualties (decompression illness) were evacuated from the cayes (Table 7).

Of the 89 CASEVACs of British military personnel from jungle locations, 41 (46\%) were for accidents, $24(27 \%)$ were heat casualties, 8 were for food poisoning and 8 for medical problems ( $9 \%$ each), $5(6 \%)$ had been bitten or stung and $3(3 \%)$ had surgical problems.

\section{Discussion}

The data on casualty types collected during the first 2 full years of Army helicopter casualty evacuation in Belize might be used to ensure provision of an appropriate service in the future, and possibly to attempt to reduce future casualty rates. Every evacuation flight, particularly at night, exposes both crew and medical staff to personal risk, and of course involves significant financial cost.
The primary role for 25 Flight AAC is evacuation of British military casualties, who are predominantly personnel undergoing jungle training. In order to carry out CASEVAC from remote jungle locations, helicopters should be fitted with task-specific equipment which is currently lacking in the present aircraft, namely winching equipment capable of lifting casualty and attendant; sufficient cabin space to allow in-flight resuscitation and treatment; and capacity for two pilot night operations whilst carrying patient and attendant, to reduce the potential hazards inherent in night jungle landings.

The evacuation of local or foreign casualties is a lesser, but still significant, priority. Such evacuations predominate from town or caye locations, which do not present the same technical difficulties as flight into jungle landing sites.

Whilst the majority of British military casualties evacuated by helicopter are victims of injury or accident in the jungle, there has been a significant number of CASEVACs for potentially preventable problems. Over a quarter of the evacuations from the jungle were for heat illness, and a further $9 \%$ were due to food poisoning. Education of all personnel, and in particular the chain of command, concerning risks of heat illness and the importance of field hygiene, should remain a vital component of pre-deployment briefings. A total of 14 evacuations of military casualties (from jungle and mountains) were for medical or surgical problems.

\section{Acknowledgments}

My thanks to Sgt TA Stronge, RAMC, BATSUB Practice Manager, for collection of the raw data on helicopter casualty evacuations in Belize.

\section{REFERENCES}

1. Greaves I, Dyer P, Porter K. Handbook of Immediate Care. London: W B Saunders Company Ltd., 1995.

2. ANDREw DR. Helicopter Ambulances in Critical Care. J R Army Med Corps 1994; 140(1): 22-5. 